\title{
Hong Kong Films in the Social Evolution after 1997
}

\author{
Jing Yi \\ Management Department \\ Beijing Film Academy \\ Beijing, China
}

\author{
Guannan E \\ School of Fashion and Communication \\ Beijing Institute of Fashion Technology \\ Beijing, China
}

\begin{abstract}
Over the past 20 years from 1997 to 2007, based on the choice of history and the development of mutually beneficial mutual needs, the mainland and Hong Kong film cooperation has experienced a complicated change of process, on the base of this echo the mainland film of Reform and Opening-up policy. Hong Kong's society has undergone great changes, Hong Kong's complex cultural identity has fluctuated during the period, and Hong Kong's self-identity has been reconstructed. In the post-colonial era, Hong Kong sought its cultural home in the form of film. At present, the mainland and Hong Kong co-productions have developed into the mainstream products of the two markets, and have basically generated the unique and effective core competitiveness of the industry. It has become a remarkable achievement in the development of film development and foreign culture communication since 1997.
\end{abstract}

Keywords-Hong Kong films; co-productions; film industry

\section{INTRODUCTION}

On July 1, 1997, Hong Kong returned to China and "1997" has become a special time and directly marked the transformation of Hong Kong as the aspects of politics, economy and culture. Nowadays, the sovereignty of Hong Kong has returned for 20 years, during which Hong Kong society has been experienced new changes and entered into a wholly-new development situation. With the honorable title of "Eastern Hollywood", Hong Kong film industry has shot abundant and special Hong Kong films and other coproduction films under the constant cooperation with mainland and beneficial policies during the past 20 years.

Twenty years have been passed, and it needs us to survey the social changes in the Hong Kong film after "1997" as well as the interaction effect and coalesce of Hong Kong films and Mainland films. Therefore, this paper will explore the reconstruction of Hong Kong self-status under the condition and occasions of its social evolution and complicated cultural statuses through theoretical and practical levels after "1997”.

\section{HISTORICAL ORIGIN AND TRANSFORMATION OF HONG KONG FILM}

\section{A. Evolution of Hong Kong Film before 1997}

In November, 1985, China and Britain signed SinoBritish Joint Declaration and declared that China resumed the exercise of sovereignty of Hong Kong. In the same year,
Shaw Brothers (Hong Kong) Company retreated from film industry and marched into TV industry. In 1986, Mandarin films totally retreated from Hong Kong films and Cantonese films were in booming status. Since then, Hong Kong films have reached their peak, which is the "Golden Ten Years" memorized by Hong Kong filmmakers and fans till now. During the "Golden Ten Years", there were lots of heroes. Represented by A Better Tomorrow (1986) emerging in the middle of 1980s, such martial arts films, hooligan films, new Chinese swordplay films (Fei-hung Wong) in the 1990s, "reasonless films" of Stephen Chow in the 1990s and other love comedies, films of comedy and martial arts, films of gunplay, erotic films, ghost films were the last prosperity before "1997". However, any type of films or relative discussion has a close relationship with its social development and cultural changes. They also have their specific social culture and cultural connotation.

Before "1997", there were many films reflecting the doubts, worries and pessimistic attitudes towards the return of Hong Kong through various forms and metaphors such as Chungking Express (1994), Summer Snow (1995), Comrade: Almost a Love Story (1996), Made in Hong Kong (1997) and too many ways to be No.1 (1997). Before "1997", people were all worried about "when would Hong Kong films die?1" However, the return of Hong Kong was certain and films in that period all expressed their worries and doubts.

\section{B. Transformation of Hong Kong Films after 1997}

1) Post-colonialism: To change the default, After "1997" and according to the viewpoints of post-colonialism, the colonized must be caught in seeking self-culture when colonists leave. "1997 complex" arouses Hong Kong people to think about their cultural status-How to determine their cultural orientation? How to seek their culture through residual historical memory?

For one example, Chen Guo tried to release The Longest Summer, which directly depicted the return of Hong Kong, on the last day of 1997. Superficially, there were six-time firework shows, but such firework shows were just a kind of image and they represented the loneness, desperation and doubts and worries about its status and future. As for Chen Guo, there were even lots of loneness and worries. Apart from lots of political irony, there were real scenes such as sovereignty handover ceremony, people's liberation army 
going into town and the open to traffic of Tsing Ma Bridge. Social issues like recognition of Hong Kong people, future planning and contradiction between Hong Kong and Mainland were fully expressed in this film.

2) "The die of hong kong films": In the middle of 1990s, Hong Kong films were in downturn and Hong Kong Ming's Monthly Magazine even used the title of "The Die of Hong Kong Film" to point out the dangerous occasion of Hong Kong film. Maybe its title a little shocking, but the present Hong Kong films really lost the golden development period of 1980s. In 1997, Hong Kong returned and for Hong Kong films, this year was bleak and full of difficulties. Along with the strike of Hollywood films, Hong Kong films lost lots of audience and the attendance of cinema and trading value of copyright were worse than before. South Korean, Japan and other regions were all against Hong Kong films. The severe loss in Taiwan made Hong Kong lose its biggest market. Only depending on own markets, Hong Kong films were unable to guarantee the normal shooting and playing. The severe market conditions directly led to the diminishment of films. In the 1980s, the annual amount was over 200, but in the middle of 1990s, the amount was 103. During that period, Asian financial crisis broke out and lots of excellent filmmakers all left Hong Kong to seek overseas chances, which made the situation of Hong Kong films even worse.

\section{CASE RESEARCH OF HONG KONG FILMS AFTER 1997}

As for most of common Hong Kong people, 1997 is not only an ambiguous future, but also breaks off their usual time experience and historical views in a certain degree. In other words, they are worried and nervous to wait the arrival of "1997". Hong Kong society will encounter the void of history and time for a while. Such sprit experience, cultural condition and social evolution after returning will be definitely showed in the films of "post-1997". The author will narrate this from the following three types of films.

\section{A. Family Films}

After returning, social changes of Hong Kong will definitely lead to the changes of family life, while these changes are inevitable to be expressed through films. Film Echoes of the Rainbow guided by family story is actually the "microcosm of history". In these films, the traditional families become the epitome of their state and society.

Film Echoes of the Rainbow narrates a family of four in Hong Kong Sham Shui Po from 1967 to 1977. The Hong Kong spirit of "All for One, One for All" and unyielding striving spirit reappear. Apart from family, the relation between one home and another constitutes human kindness and the relation of neighborhood becomes the continuance of family relation. Eric Tsang's film 72 Tenants of Prosperity expresses the human kindness in Hong Kong through humorous and comedic life of citizens. The relations between husband and wife, father and son, friends are more like an epitome of Hong Kong society. The expression and description of human relationship mean the recognition of family relationship. At any key time, family and friends can always stick together to fight and return to a harmonious atmosphere.

\section{B. Hong Kong Action Films}

In "The Requisition of Violence and Power-Cultural Explanation of Hong Kong Gangster Films", Lu Xin analyzes that the cause for Hong Kong gangster films to be welcomed is that this satisfies people's admiration of violence and desire of power through the requisition of violence and power. People can release their repression and conflicts in daily life and present social order through the imagination of films. Comparing with the initial gangster films, film I Want to Be You directed by Andrew Lau construct a black world, which is far from reality but reflects reality and a new value order is rebuilt. As to previous films, polices and gangsters all have distinctive characteristics. Polices are the keepers of order and adhere to their own principle, while the gangsters also have their own principle-"code of brotherhood". The relations between the boss and other brothers are leadership and obedience. Brothers will take boss's desire as their mission and even consider their boss as spiritual idol. However, in film I Want to Be You, the power of polices as the keepers of orders is weakened and even disappears. The bound between polices and gangsters is obscure and polices will take all measures to achieve their goals. Gangsters in the team of polices can also help to keep social order and it will be impossible to distinguish "good men" and "bad men" just from their identities and social statuses. The roles and figures are no more separated but a more complicated social system.

In the films of The Longest Nite (1998), I Want to Be You(2002), Infernal Affairs II(2003), Infernal Affairs III (2003), Underworld Society(2005), Overheard (2009), The White Storm(2013), Port of Call(2015), Paradox(2017), cause and effect and circular special themes are embodied through identity tracing. It tries to link the helplessness of reminiscence and the fate of doubt in the historical and personal conflicting time. The initial romance and black idealism tend to a dark realism and the transformation of gangster films represents the calm thinking of social values, which means that the mentality of Hong Kong people is becoming more and more mature. Though such thinking has some pains, such films will have more optimistic meanings comparing to avoiding problems.

\section{Comedy Films}

Comedy films are always the traditional films in Hong Kong film industry. No matter the native characteristics of Cantonese comedies of $\mathrm{Xu}$ Brothers in 1970s or the welcomed Mandarin films with the "reasonless style" of Stephen Chow in 1991s are all the collective memory Hong Kong comedy films. When mentioning about Hong Kong comedy films, Stephen Chow will be the first topic. He has an accurate understanding towards mass mentality under such a special social background in 1990s. His films also embody the anxiety, abreaction, exile and return before and after 1997. 
Stephen Chow once acted the leading role in Fight Back to School, Hail the Judge, Kung Fu Hustle, Chang Jiang Qi Hao and other films. Stephen Chow, Jackie Chan and Chow Yun-Fat were called "Two Chows and One Chan". They were once the guarantee to have a good box office and were the excellent directors who could "shoot Hong Kong in the views of outside Hong Kong". After returning, Stephen Chow-style comedy films had an obvious transformation. They were no more the gangsters or other exaggerated characters, but they returned to love and smiling with tears is the new comedy style that Stephen Chow pursued.

\section{Co-productions of Hong Kong and Mainland China}

Since the establishment of the "China Film CoProduction Corporation" in 1979, until 2017, the coproductions of mainland China and Hong Kong have been reach nearly 1000 . From 1979 to 1999 , there are about 19 parts per year, about 35 from 1999 to 2003.The signing of CEPA (Closer Economic Partnership Arrangement) in 2003, the number of co-productions between Hong Kong and the mainland has been growing rapidly every year. In 2016, there were 89 co-production films was released in mainland China. Among them, the co-production films of mainland and Hong Kong were 54, which accounted for $56 \%$ of the total number of co-productions as in "Table I".

TABLE I. 2011-2016 CO-PRODUCTION, CO-PRODUCTION WITH HONG KONG, AND BOX OFFICE

\begin{tabular}{|l|l|l|l|l|l|l|}
\hline \multicolumn{1}{|c|}{ Year } & $\mathbf{2 0 1 1}$ & \multicolumn{1}{|c|}{$\mathbf{2 0 1 2}$} & $\mathbf{2 0 1 3}$ & $\mathbf{2 0 1 4}$ & $\mathbf{2 0 1 5}$ & $\mathbf{2 0 1 6}$ \\
\hline Co-productions & 73 & 66 & 55 & 77 & 94 & 96 \\
\hline $\begin{array}{l}\text { Cooperation } \\
\text { with } \\
\text { Hong Kong }\end{array}$ & - & 39 & 34 & 46 & 48 & 54 \\
\hline $\begin{array}{l}\text { HongKong } \\
\text { coproduction } \\
\text { ratio }\end{array}$ & - & $59 \%$ & $62 \%$ & $60 \%$ & $51 \%$ & $56 \%$ \\
\hline $\begin{array}{l}\text { Countries and } \\
\text { regions involved }\end{array}$ & - & 7 & 7 & 12 & 13 & 17 \\
\hline $\begin{array}{l}\text { Accounts for the } \\
\text { annual box } \\
\text { office share }\end{array}$ & $11 \%$ & $8.9 \%$ & $15 \%$ & $21 \%$ & $24 \%$ & $32 \%$ \\
\hline
\end{tabular}

Symbol of the emergence of the mainland and Hong kong co-productions is China mainland and Hong Kong Zhongyuan pictures, filming the kung fu movie The Shaolin Temple (1982) in 1982, Hong Kong received more than HK\$ 16000000 at the box office, broke the record for the Hong Kong kung fu movie set by the Jackie Chan The Young Master (1980). First half of the 90s, Hong Kong and mainland China co-productions once reached the culmination of the history, not only produced more than 30 units, and 1992-1993, Once Upon a Time in China III (1993), Farewell My Concubine (1993) once cover the mainland and Hong Kong mainstream at the box office. But in 1994 as the mainland introduced ten parts accounts, in the face of Hollywood blockbusters, in pieces of relative lack of competitiveness, only Stormriders (1998), Dragon Town Story (2003) sales well.

Since 2003, through the Hero (2002), A World Without Thieves (2004), The Warlords (2008), The Banquet (2006), Red Cliff (2008) and so on, the China film group, Huayi Brothers and other institutions on the mainland comprehensive intervention practice, financing, production, distribution and other industries have begun to cooperate, and even equality and mutual benefit to master control the Hong Kong Media Asia, Emperor movie institutions.

Therefore, after 20 years of complicated fumble, the mainland and Hong Kong co-productions have finally developed into an equal and mutually beneficial relationship, and finally formed unique and effective core competitiveness.

\section{CONCLUSION}

Due to the stable political situation in the past seventeen years, favorable economic development trend, successive culture of Hong Kong and Chinese mainland, broad film market in Chinese mainland, cultural interactions of settledown mainlander, as well as favorable film policies etc. Hong Kong films have already walked out from the "1997 complex" before return, and started the new imagination and cognition about the subject identity, for instance, the cognition of returning families about kinship, friendship and harmonious interpersonal relation. However, Hong Kong films still present the old-fashioned, helpless, doubtful and fateful historical concepts and unique spiritual qualities.

From separation to integration, from isolation to harmony, Hong Kong films confirmed the local cultural character and reconstruct the modernistic local spirit by re-inspecting the cultural characteristics. During this period, Hong Kong films mixed the reasonless comedies written due to the residual colonial awareness, jesting films, as well as the nostalgia films based on the subject consciousness. It not only continues the cultural heritage of the nation, but also reflects the Hong Kong consciousness and experience.

Nowadays, opinions on the national properties, family relation, traditional culture and foreign culture in Hong Kong films are distinct and unified. It can integrate the mainland culture actively based on the traditional Chinese culture, and form good interactions and cultural resonance between Taiwan and mainland. Meanwhile, with the hot showing of co-productions in recent years, Hong Kong films are also confronted by some criticisms, for instance, following the mainland culture blindly, gradual blurring of Hong Kong image, etc. As for Hong Kong films, how to find the cultural integration and common mentality in contemporary era is a cultural dilemma of Hong Kong films.

\section{ACKNOWLEDGMENT}

In this paper, the research was sponsored by the National Social Science Fund of China (Project No. 16ZD04).

\section{REFERENCES}

[1] Bordwell D. Planet Hong Kong: popular cinema and the art of entertainment[J]. Variety Movie Reviews, 2000, 51(1):215-216.

[2] Chen Xihe, Liu Yuqing. Hong Kong film in the new pattern of Chinese film - and the rethinking of post-colonial theory [J]. Literature and art research, 2007(11):14-23.

[3] Fang Fang, Madness of Hong Kong Films - A Representation and Social Source of Film[D]. Nanjing Normal University, 2007. 
[4] Hu Die: Cultural Identity in Hong Kong Films in Transitional Period[D].Fudan University, 2008.

[5] Jia Leilei: Cultural Recognition of National Image and its Realistic Meaning[J]. Studies on Culture \& Art, 2008, 01(1):186-192.

[6] Sun Weichuan, Luo Renjing. "After 97" Hongkong film immigration expression and identity reconstruction of contemporary film [J]., 2015 (10): 110-112. 